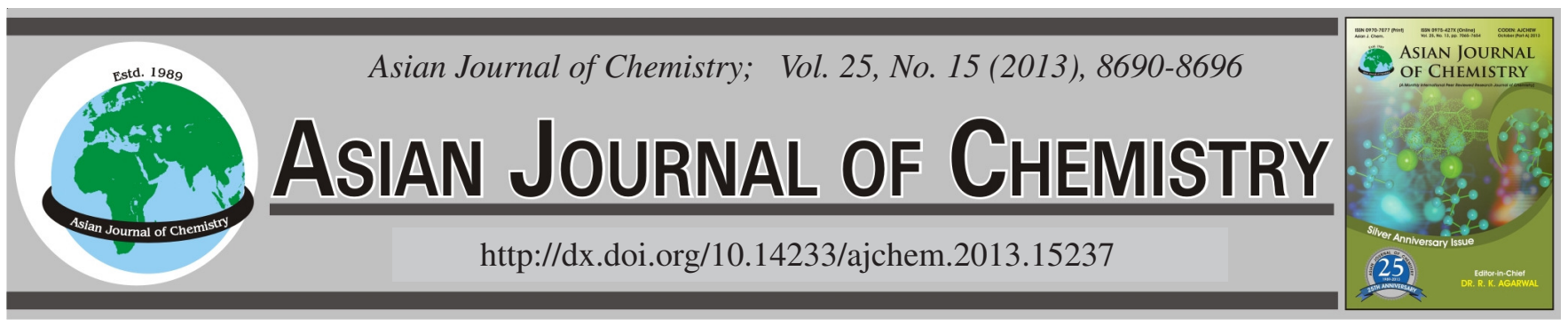

\title{
Evaluation of Corrosion Inhibition Performance of Zinc Oxide and Sodium Nitrite in Quarry Dust Concrete
}

\author{
M. DEVI ${ }^{1, *}$ and K. KANNAN ${ }^{2}$
}

${ }^{1}$ Department of Civil Engineering, Paavai Engineering College, Namakkal-637 018, India

${ }^{2}$ Department of Chemistry, Government College of Engineering, Salem-636 011, India

*Corresponding author: E-mail: devimcivil@gmail.com

(Received: 29 January 2013;

\begin{abstract}
The objective of this study is to discuss the inhibitive behaviour of two inorganic corrosion inhibitors namely sodium nitrite, an anodic inhibitor and zinc oxide, a cathodic inhibitor on steel embedded in concrete containing quarry dust as fine aggregate. Each inhibitor was evaluated for various strength properties such as compressive strength, split tensile strength, flexural strength and bond strength in addition to water absorption capacity. The performance of the inhibitors on corrosion resistance was studied using impressed voltage method, rapid chloride ion penetration test, AC impedance measurement and weight loss measurement. The surface analysis of the embedded steel was carried out by scanning electron microscope analysis. Based on the results of strength and durability tests the optimum percentage of inhibitors to be added in quarry dust concrete was determined. The experimental results demonstrate that addition of inhibitors enhances the corrosion resistance properties and does not have any adverse effects on strength properties.
\end{abstract}

Key Words: Concrete, Quarry dust, Corrosion, Inhibitor, Chloride diffusion, Accelerated corrosion, Resistance.

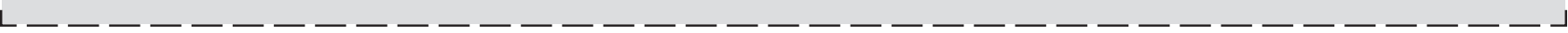

\section{INTRODUCTION}

The demand for natural sand in the construction industry has consequently increased due to the extensive use of concrete resulting in the reduction of sand sources and increase in price. Thus, an investigation is needed to identify a suitable substitute that is eco-friendly and inexpensive and in this connection the use of quarry dust as fine aggregate has occupied a promising factor in the preparation of concrete ${ }^{1}$. Quarry dust, a byproduct from the crushing process of stones (Blue metal) which is available abundantly from rock quarries at low cost in many areas can be an economical alternative to the river sand ${ }^{2}$. The strength and durability properties of concrete containing hundred per cent quarry dust as fine aggregate was studied ${ }^{3,4}$. They concluded that strength properties of concrete made of quarry dust are nearly $10 \%$ more than conventional concrete. The use of quarry dust as fine aggregate in concrete will reduce not only the demand for natural sand but also reduces the environmental load due to disposal problems ${ }^{5}$. However, in order to attain the desired workability at constant water cement ratio, super plasticizers has to be used in quarry dust concrete $e^{6,7}$. Concrete produced using quarry dust along with plasticizer shows improvement in compressive strength, higher flexural strength, abrasion resistance and unit weight which are very important for reducing corrosion or leaching ${ }^{8}$.
Corrosion of steel rebar in concrete is a serious problem from both economical and structural integrity aspects ${ }^{9-11}$. Initiation of corrosion takes place either due to reduction in alkalinity arising from carbonation or breakdown of the passive layer by the attack of chloride ions ${ }^{12}$. Once corrosion initiates, it propagates rapidly and subsequent corrosion of steel produces rust products, which have a volume 3-8 times greater than that of the original metal ${ }^{13}$.Many structures in adverse environments have experienced unacceptable loss in serviceability of safety earlier than anticipated, due to the corrosion of reinforcing steel and thus need replacement, rehabilitation or strengthening ${ }^{14}$. Corrosion inhibitors are widely used to delay or retard corrosion of reinforcing steel in concrete ${ }^{15-18}$. According to NACE (National Association of Corrosion Engineers) inhibitors are substances which, when added to an environment, decrease the rate of attack on a metal. The most common amongst these are the inhibitors based on inorganic compounds. These inhibitors generally provide protection by an interfacial process, i.e., they reinforce the protective film of ferric oxide around the steel by oxidizing ferrous ions ${ }^{19,20}$. Based on the mode of action, corrosion inhibitors belong to three classes namely anodic inhibitors, cathodic inhibitors and mixed or ambiotic inhibitors ${ }^{21,22}$. Some researchers ${ }^{23-25}$ have investigated the mechanism of inhibitors and reported that inhibitors can act as anodic inhibitors block the corrosion reaction of the 
chloride-ions by chemically reinforcing and stabilizing the passive protective film on the steel (e.g. nitrites). Cathodic inhibitors react with the steel surface to interfere with the reduction of oxygen (e.g. zinc oxide) or ambiodic inhibitors suppressing both anodic and cathodic sites by forming an adsorptive film on the metal surface (e.g. amines and fatty acids). In this study, the multi-functional benefits of an anodic inhibitor, sodium nitrite and a cathodic inhibitor, zinc oxide at the dosage of 1,2, 3 and $4 \%$ by weight of cement in concrete containing quarry dust as fine aggregate are presented and discussed with regard to the corrosion protection of embedded steel and resistance to chemical attack.

\section{EXPERIMENTAL}

The cement used was Ordinary Portland Cement (43 Grade) conforming to IS 8112-1989. Locally available wellgraded quarry dust, conforming to Zone-II of IS 383-1970 having specific gravity 2.68 and fineness modulus 2.70 was used as fine aggregate. Natural granite aggregate having density of $2700 \mathrm{~kg} / \mathrm{m}^{3}$, specific gravity 2.7 and fineness modulus 4.33 was used as coarse aggregate. High yield strength deformed $16 \mathrm{~mm}$ diameter bars of Fe 415 grade conforming to IS 1786 was used for pullout and corrosion tests. To increase the workability of quarry dust concrete commercially available super plasticizer ROFF 320 at the dosage of $0.4 \%$ by weight of cement has been used. The inhibitors used were sodium nitrite and zinc oxide at the dosage of $1,2,3$ and $4 \%$ by weight of cement. To attain strength of $20 \mathrm{~N} / \mathrm{mm}^{2}$ a mix proportion was designed based on IS 10262-1982 and SP23:1982(21). The mixture was $1: 1.517: 3.38$ with water cement ratio 0.45 .

Methodology: Concrete cubes of size $150 \mathrm{~mm} \times 150 \mathrm{~mm}$ $\times 150 \mathrm{~mm}$, beams of size $500 \mathrm{~mm} \times 100 \mathrm{~mm} \times 100 \mathrm{~mm}$, cylinders of size $150 \mathrm{~mm}$ diameter and $300 \mathrm{~mm}$ long were cast for compressive, flexural and split tensile strength tests. After $24 \mathrm{~h}$ the specimens were demoulded and subjected to water curing. After 28 days curing the specimens were tested as per IS: 516-1964. Cylinders of size $150 \mathrm{~mm}$ diameter and $300 \mathrm{~mm}$ long with rods of $70 \mathrm{~cm}$ length kept at the centre were used for determination of bond strength. Water absorption of hardened concrete specimens was calculated based on ASTM C642-81. Cubes of size $150 \mathrm{~mm} \times 150 \mathrm{~mm} \times 150$ $\mathrm{mm}$ were cast and after 28 days curing the cubes were taken out and dried in an oven at $105^{\circ} \mathrm{C}$ for $24 \mathrm{~h}$. The dried specimens were cooled to room temperature $\left(25^{\circ} \mathrm{C}\right)$, weighed accurately and noted as dry weight. Dry specimens were immersed in water and the weight of the specimens at predetermined intervals was taken after wiping the surface with dry cloth. This process was continued till constant weight is obtained in two successive observations. Concrete cylinders of size $75 \mathrm{~mm}$ diameter and $150 \mathrm{~mm}$ length with centrally embedded a high yield strength deformed (HYSD) steel bar of $16 \mathrm{~mm}$ diameter were used to assess the corrosion protection efficiency under accelerated test conditions, $\mathrm{AC}$ impedance measurement and weight loss measurement. After 28 days curing the specimens were subjected to acceleration corrosion process in order to accelerate reinforcement corrosion in the saline media $(3 \%$ sodium chloride) under a constant voltage of $6 \mathrm{~V}$ from the D.C power pack.
In AC impedance spectroscopy measurement, AC. signal is applied to the embedded rebar and the response is monitored in terms of phase shift of the current and voltage components and their amplitude. The potential of the rebar was measured periodically using a high input impedance multimeter. Impedance measurement was made using three electrode arrangements. Stainless steel electrode of size $10 \mathrm{~mm} \times 80 \mathrm{~mm}$ was used as an auxiliary electrode and saturated calomel electrode was used as a reference electrode. Rebar embedded in concrete acted as a working electrode. Chloride solution was used as a contacting solution to reduce the contact resistance between the electrode assembly and the concrete.

For weight loss measurement the cylinders were immersed in $3 \% \mathrm{NaCl}$ solution under alternate wetting (3 days) and drying (3 days) conditions over a period of 90 days. At the end of 90 days the cylinders were broke open and the final weight of the specimens was taken and the loss in weight was calculated. From the weight loss obtained corrosion rate is calculated. The RCPT is performed by monitoring the amount of electrical current that passes through concrete discs of 50 $\mathrm{mm}$ thickness and $100 \mathrm{~mm}$ diameter for a period of $6 \mathrm{~h}$. A voltage of $60 \mathrm{~V} \mathrm{DC}$ is maintained across the ends of the specimen throughout the test. One lead is immersed in a sodium chloride solution $(0.5 \mathrm{~N})$ and the other in a sodium hydroxide solution (0.3). The total charge passed through the cell in coulombs has been found in order to determine the resistance of the specimen to chloride ion penetration.

All the tests were conducted on a minimum of three replicate specimens after 28 days curing and the average values are reported. The identification of the specimens is shown in Table-1.

\begin{tabular}{cl}
\multicolumn{1}{c}{ TABLE-1 } \\
\multicolumn{1}{c}{ IDENTIFICATION OF THE SPECIMENS } \\
\hline C & $\begin{array}{l}\text { Control specimen-Concrete with quarry dust as } \\
\text { fine aggregate }\end{array}$ \\
Z1, Z2, Z3, Z4 $\begin{array}{l}\text { Quarry dust Concrete with zinc oxide at 1, 2, 3 and } \\
4 \%\end{array}$ \\
S1, S2, S3, S4 $\begin{array}{l}\text { Quarry dust concrete with sodium nitrite at 1, 2, 3 } \\
\text { and 4\% }\end{array}$
\end{tabular}

\section{RESULTS AND DISCUSSION}

Compressive, split tensile, flexural and bond strength: The compressive, split tensile, flexural and bond strength results obtained after 28 days are shown in Figs. 1-4, respectively. The compressive strength results after 28 days curing are shown in Fig. 1. From the figure it is evident that $1 \%$ addition of zinc oxide shows $7.8 \%$ increase in the compressive strength, while the addition of $2 \%$ of this inhibitor gives increase of $11 \%$ and this yields the maximum increase in the strength value. Further, addition of zinc oxide to 3 and $4 \%$ gives 4.6 and $0.7 \%$, respectively which yields a comparatively lower value than using $2 \%$. Similarly, the addition of sodium nitrite gives the maximum increase in the strength value at $2 \%$ dosage and the increase in strength values is $10.5 \%$. In accordance with Fig. 2, it is understood that addition of $2 \%$ of zinc oxide and sodium nitrite shows the maximum increase in split tensile strength value by 7.8 and $7 \%$. Fig. 3 showed that the maximum increase in the flexural strength is given by 

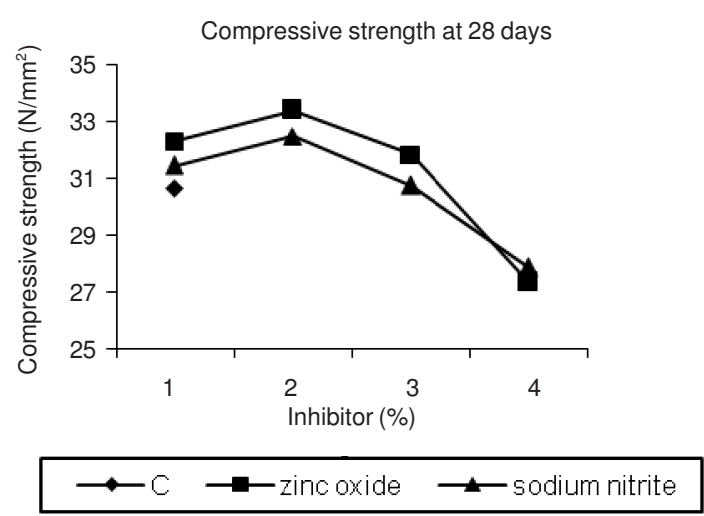

Fig. 1. Compressive strength development
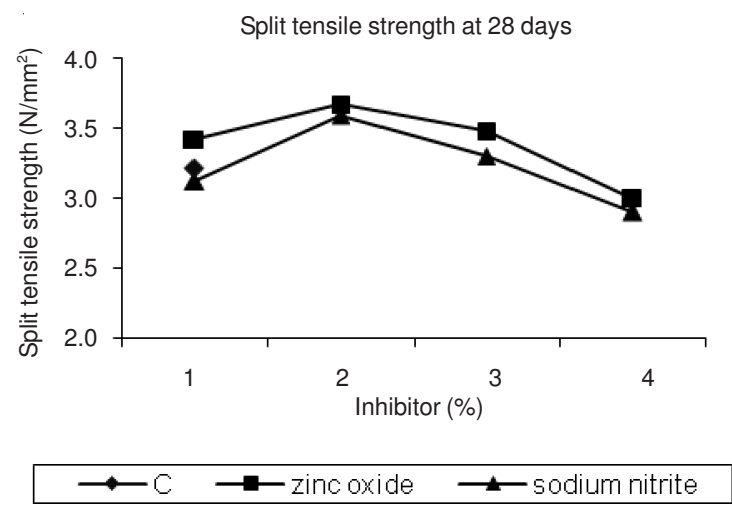

Fig. 2. Split tensile strength development

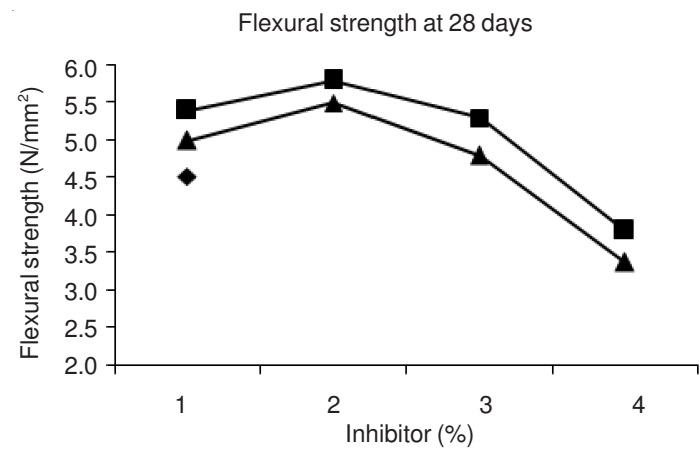

$\longrightarrow \bullet \mathrm{C} \longrightarrow \boldsymbol{n}$ zinc oxide $\longrightarrow$ sodium nitrite

Fig. 3. Flexural strength development

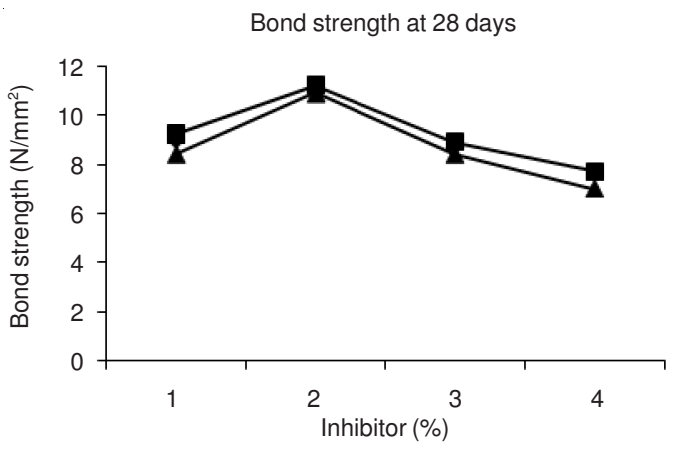

$\rightarrow \mathrm{C} \rightarrow$ zincoxide $\rightarrow$ sodium nitrite

Fig. 4. Bond strength development

$2 \%$ addition of zinc oxide and sodium nitrite. The strength values are increased by 6 and $5.8 \%$, respectively. The bond strength test results at 28 days are shown in Fig. 4. The specimens with $2 \%$ addition of zinc oxide, sodium nitrite show a maximum increase in the bond strength by 10.3 and $8.4 \%$. However, by increasing the inhibitor to 3 and $4 \%$ there was a marginal reduction in the strength values.

From the results of the strength tests, it is observed that addition of inhibitors does not show any adverse effects on strength properties and also there was a slight improvement in strength properties up to certain percentage. The inorganic inhibitors zinc oxide and sodium nitrite show improvement in strength properties for 1 and $2 \%$ dosage since the total porosity of the paste was lower in these percentages. For 3 and $4 \%$ addition of inhibitors, there was a slight reduction in strength due to decrease in the degree of hydration and therefore, a higher capillary porosity or a change in the cement microstructure takes place ${ }^{16}$.

Water absorption: Fig. 5 shows the water absorption capacity of various percentages of inhibitors after 28 days curing. The control specimen shows the highest water absorption value than all mixes. For both the inhibitors the absorption decreases as the concentration of inhibitor increases up to 2, 3 and $4 \%$ addition of other inhibitors show relatively higher absorption than the optimal percentage. However, when compared to the control specimens, the addition of inhibitors definitely produces lower absorption values.

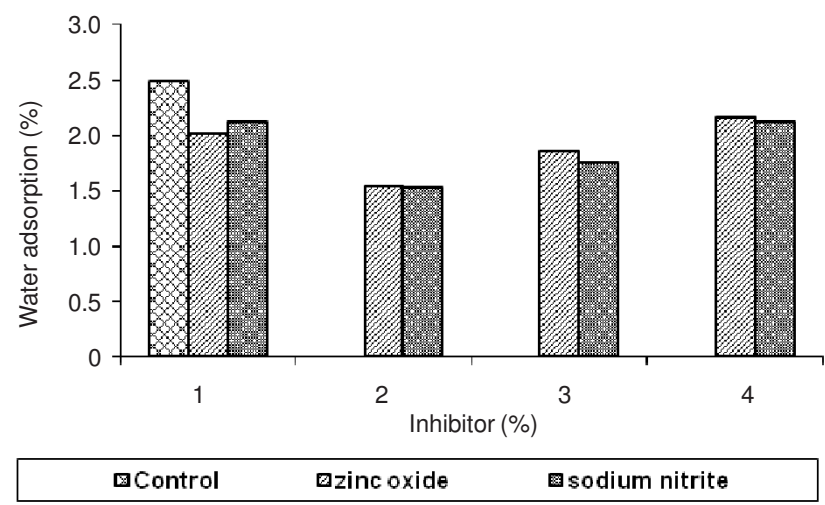

Fig. 5. Water absorption

\section{Durability tests}

Impressed voltage method: The corrosion resistance performances of the inhibitors resulted from impressed voltage measurement at various percentages with respect to time are shown in Fig. 6. The current intensity with respect to time for various percentages of inhibitors is shown in Figs. 7 and 8.

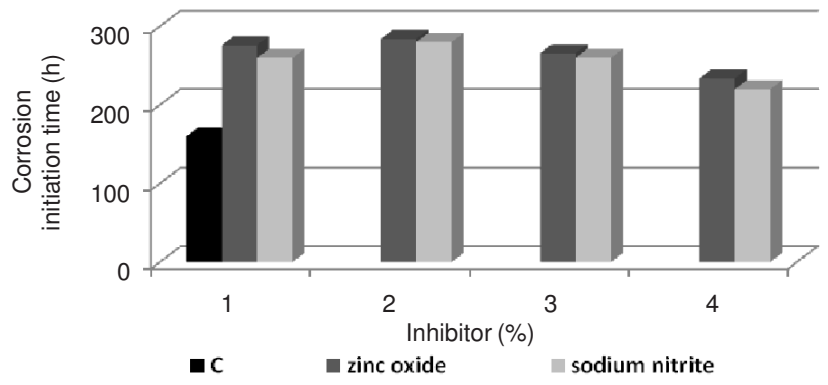

Fig. 6. Corrosion initiation time in hours 


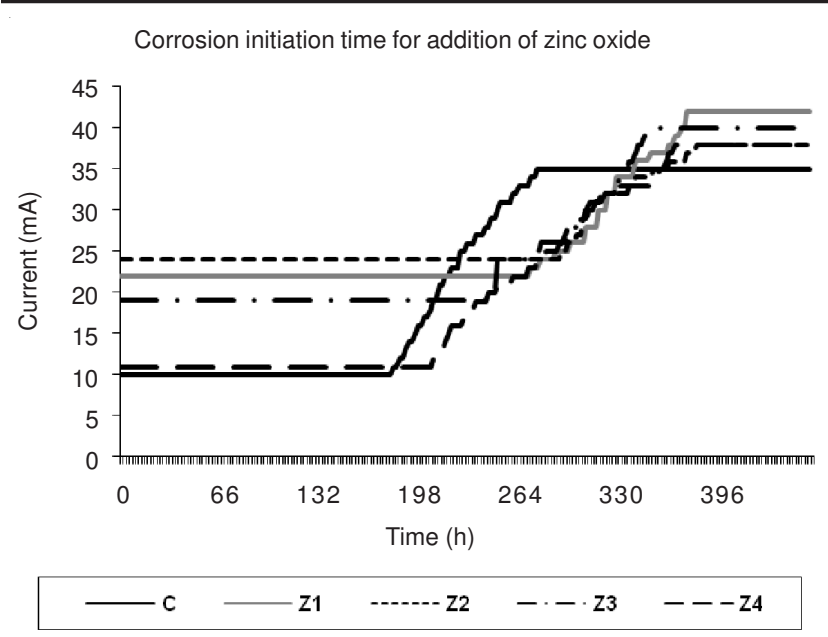

Fig. 7. Corrosion initiation time for $\mathrm{ZnO}$

Corrosion initiation time for addition of sodium nitrite

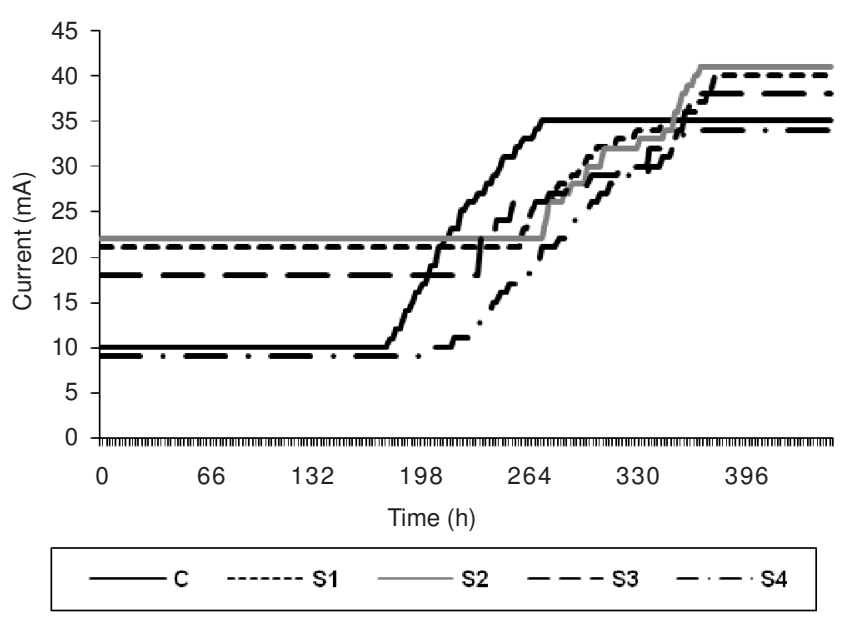

Fig. 8. Corrosion initiation time for $\mathrm{NaNO}_{2}$

The corrosion initiation time for control concrete is found to be 160 h. In accordance with Fig. 6, it is to be noted that even the minimum value of the corrosion initiation time with respect to the addition of inhibitors is slightly higher than that of the control specimens. $2 \%$ addition of zinc oxide showed $80.5 \%$ improvement and $2 \%$ addition of sodium nitrite exhibited $76.5 \%$ improvement in corrosion resistance and proved to be most effective percentage. However the corrosion resistance was slightly reduced for $4 \%$ addition of inhibitors. The impressed voltage test results show that due to the addition of inhibitors permeability of the concrete was considerably reduced and the time taken for initiation of corrosion in concrete with respect to accelerated chloride penetration has been increased significantly.

From the results it is evident that $2 \%$ addition of zinc oxide and sodium nitrite has shown maximum efficiency in corrosion resistance which was the optimal percentage to be added in quarry dust concrete to get maximum corrosion resistance.

Rapid chloride permeability test: Fig. 9 shows the chloride diffusion results of the different percentages of inhibitors. The performance of the quarry dust concrete with $1,2,3$ and $4 \%$ addition of zinc oxide are observed to be $1.42,1.66$,

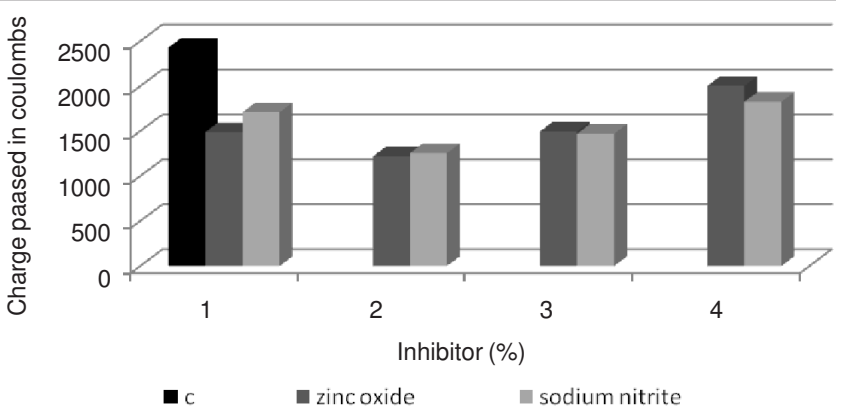

Fig. 9. Rapid chloride permeability test

1.32 and 0.88 times greater than the control specimen. Similarly, the performance of sodium nitrite is found to be 1.38 , $1.58,1.12$ and 0.75 times greater than the control specimen. From the figure it is observed that addition of $2 \%$ zinc oxide and sodium nitrite show lower coulomb values than the other mixes.

Weight loss method: Fig. 10 demonstrates the average corrosion rate calculated in mmpy for various percentages of the inhibitors from weight loss measurements. The corrosion rate observed for the control specimen was 0.093 . The results obtained from the weight loss method indicated that, $2 \%$ addition of zinc oxide and sodium nitrite have shown the lowest corrosion rate values and the decrease in corrosion rate was found to be 77.6 and $67.5 \%$, respectively when compared with control specimens.

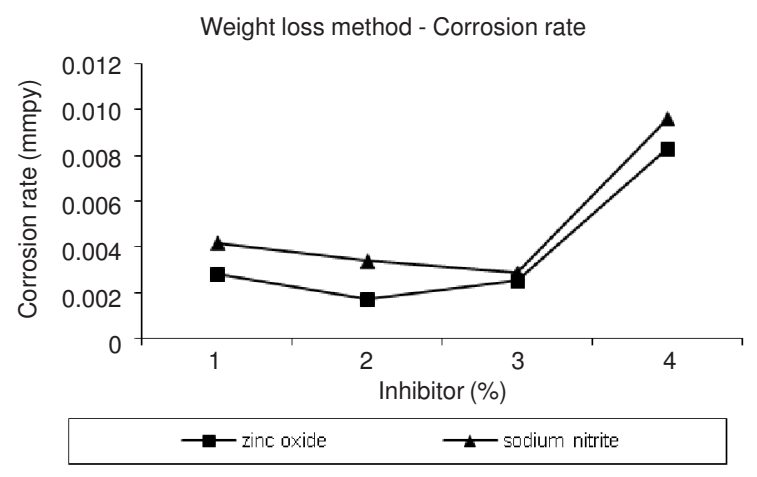

Fig. 10. Weight loss measurements for inorganic inhibitors

The inorganic inhibitors protect steel in concrete by keeping the chloride ions from reacting with the ferrous ions and cause a large anodic shift of the corrosion potential and forcing the metallic surface into passive range. The results obtained are in agreement with literature ${ }^{16}$. Further, increase in percentage of inhibitors increases the corrosion rates. However, all the inhibitor added specimens display a corrosion rate below than that of control system. The same trend was also observed in impressed voltage method.

AC impedance method: Table- 2 lists the impedance parameters such as charge transfer resistance $\mathrm{R}_{\mathrm{ct}}$ and double layer capacitance $\mathrm{C}_{\mathrm{d} 1}$ derived from Nyquist plots (Figs. 11-13) of quarry dust concrete and with optimum percentage of zinc oxide and sodium nitrite.

The $\mathrm{R}_{\mathrm{ct}}$ values for $2 \%$ of zinc oxide and sodium nitrite are found to be 1684 and $1536 \Omega \mathrm{cm}^{2}$, respectively, whereas the quarry dust concrete without inhibitor is found to be 946 $\Omega \mathrm{cm}^{2}$. The reduction is due to acceleration of corrosion by 
TABLE-2

AC IMPEDANCE PARAMETERS FOR INORGANIC INHIBITORS

\begin{tabular}{lccc}
\hline $\begin{array}{c}\text { Specimen } \\
\text { identification }\end{array}$ & $\begin{array}{c}\text { Charge transfer } \\
\text { resistance }\left(\mathrm{R}_{\mathrm{ct}}\right) \\
\text { Ohm } \mathrm{cm}^{2}\end{array}$ & $\begin{array}{c}\text { Double layer } \\
\text { capacitance } \\
\left(\mathrm{C}_{\mathrm{dl}}\right)\left(\mu \mathrm{F} / \mathrm{cm}^{2}\right)\end{array}$ & $\begin{array}{c}\text { Efficiency } \\
(\%)\end{array}$ \\
\hline Control specimen & 946 & 1049 & - \\
Zinc oxide $(2 \%)$ & 1684 & 288 & 78 \\
Sodium nitrite $(2 \%)$ & 1536 & 312 & 70 \\
\hline
\end{tabular}

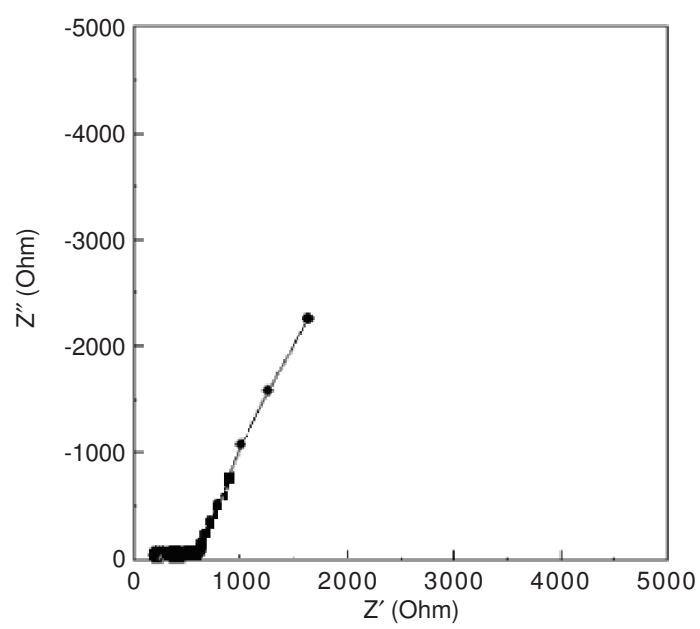

Fig. 11. Nyquist plot for quarry dust concrete without any inhibitor

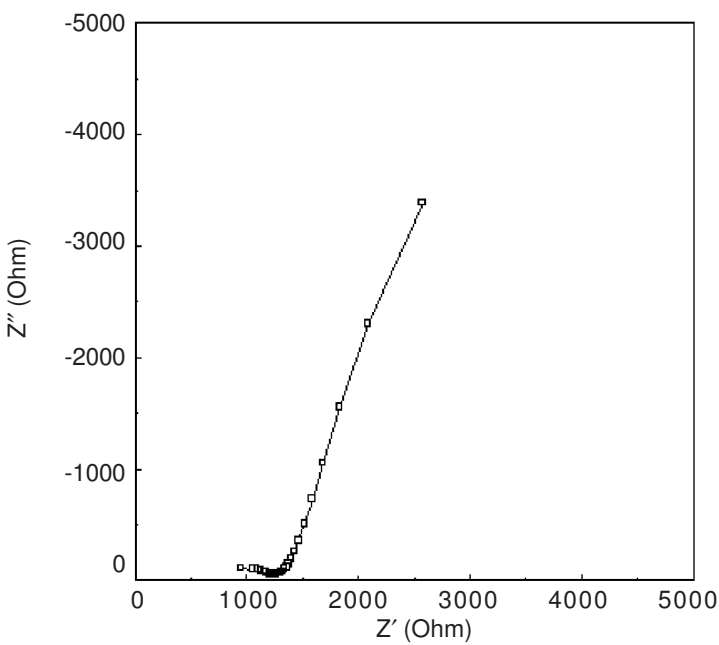

Fig. 12. Nyquist plot for $2 \%$ of zinc oxide in quarry dust concrete

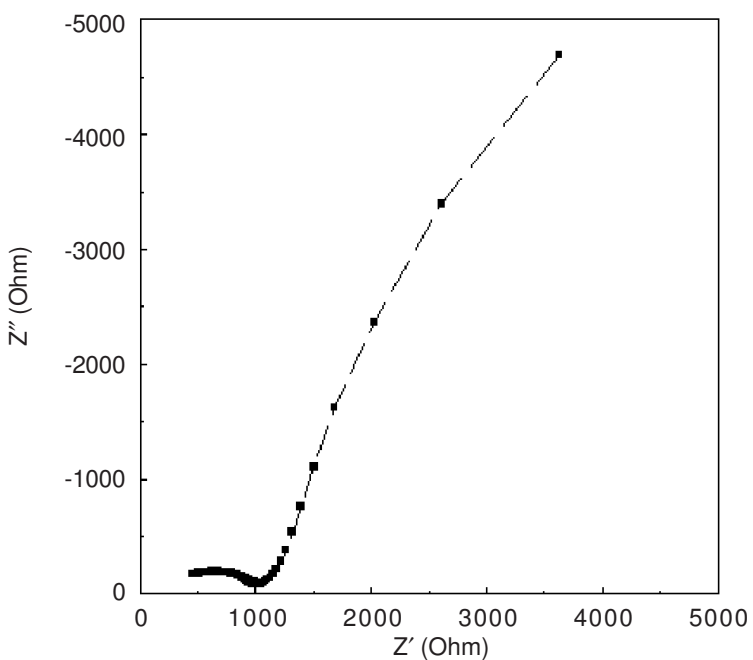

Fig. 13. Nyquist plot for $2 \%$ of sodium nitrite in quarry dust concrete chloride ions. While considering the the $\mathrm{C}_{\mathrm{dl}}$ values, addition of inhibitor shows reduction in $\mathrm{C}_{\mathrm{dl}}$ values. A good inhibitor system must show an increase in $R_{\mathrm{ct}}$ values and lesser $\mathrm{C}_{\mathrm{dl}}$ values when compared to control system. In this aspect the inorganic inhibitors were found to be more effective in controlling the corrosion rate of steel in quarry dust concrete as reported by Song and Saraswathi ${ }^{10}$.

From the values obtained by AC impedance test, it is evident that $2 \%$ addition of calcium nitrite had shown $78 \%$ increase in corrosion resistance. Similarly, sodium nitrite has shown and $70 \%$ increase in corrosion resistance, respectively at the optimum percentage of $2 \%$. The results obtained from this study are in good agreement with the results of other researchers ${ }^{21,24}$. These results also coincide with the results obtained by impressed voltage and weight loss methods.

Scanning electron microscopic studies: The surface analysis of embedded steel in quarry dust concrete and quarry dust concrete with inhibitors has been done by scanning electron microscopic studies. Fig. 14 shows the SEM image of steel specimen embedded in quarry dust concrete. The surface coverage of inhibitors with $2 \%$ addition of zinc oxide and sodium nitrite on the surface of the embedded steel are shown in Figs. 15 and 16, respectively.
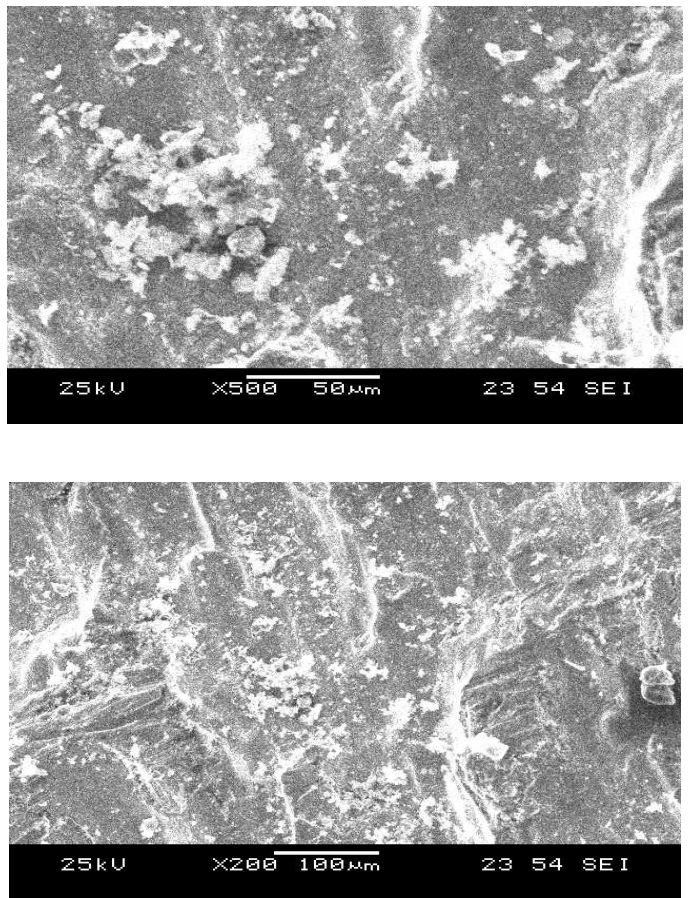

Fig. 14. SEM images of rod embedded in quarry dust concrete without inhibitor

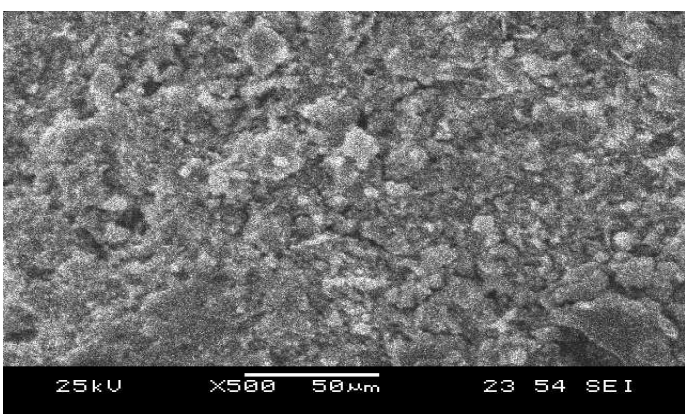




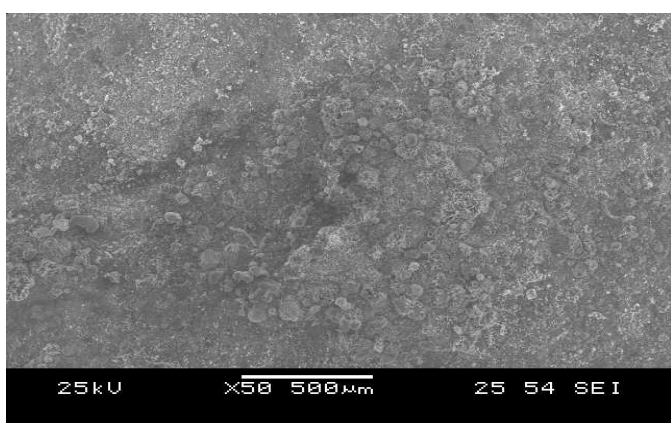

Fig. 15. SEM images of rod embedded in quarry dust concrete with zinc oxide
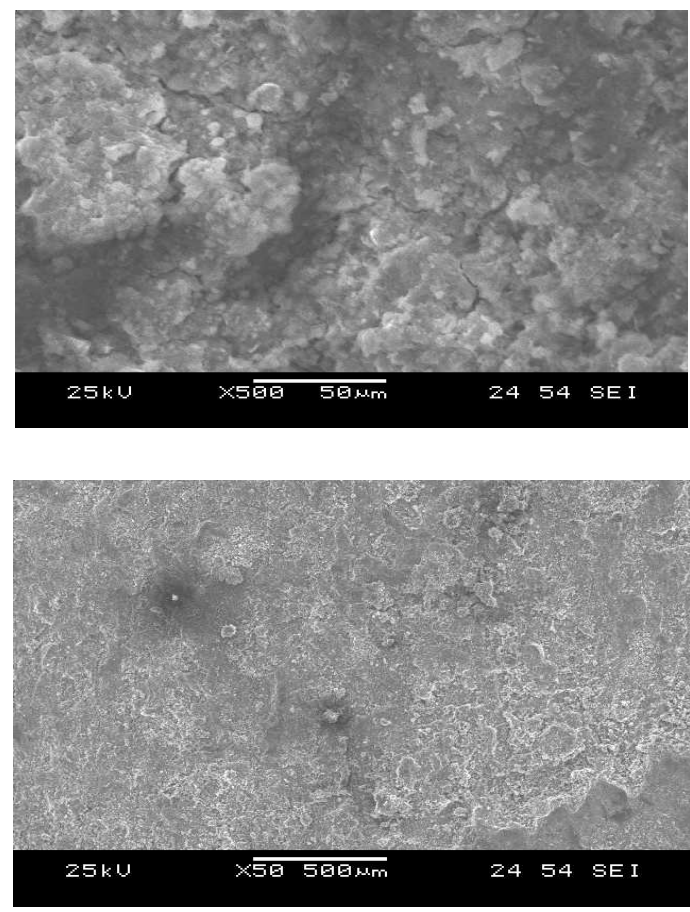

Fig. 16. SEM images of rod embedded in quarry dust concrete with sodium nitrite

In the case of steel rod embedded in quarry dust concrete without inhibitor, the SEM images (Fig. 14) show that, the steel surface is exposed without any surface coverage which makes the steel easily available for the attack of any external agents. But in the presence of inhibitors, the inhibitor reacts with steel and protecting the passive layer of the embedded steel. It could be observed from the SEM images shown in Figs. 15 and 16. Thereby, the embedded steel is effectively protected from corrosion.

This is because the zinc oxide, which is the cathodic inhibitor retards the corrosion by inhibiting the reduction of water to hydrogen gas. Zinc oxide reacts with concrete and produces calcium hydroxy zincate causing passivation of steel in concrete. This product reduces the porosity of concrete and maintains the passivity of steel when it is exposed to a medium with high chloride ion content. Sodium nitrite is the inorganic oxidizing anodic inhibitor having nitrite as the main corrosion inhibiting component, which forms a stable passive layer even in the presence of chloride ions. Thus both the inhibitors offer excellent corrosion resistance on rebar embedded in quarry dust concrete.
It could be concluded from the above results that, considering strength as well as durability criteria, the optimum percentage addition of inorganic inhibitors by weight of cement in concrete containing quarry dust as fine aggregate, is $2 \%$ for zinc oxide sodium nitrite. The following is the trend observed based on strength and corrosion resistance properties

Zinc oxide $>$ Sodium nitrite $>$ Control specimen

\section{Conclusion}

From the experimental studies, the following conclusions have been drawn.

- The concrete incorporating well graded quarry dust as fine aggregate along with suitable percentage of super plasticizer can be successfully used in the construction industry.

- The inorganic corrosion inhibitors investigated in this study did not adversely affect the strength properties of concrete. Among the various percentages of inhibitors added the specimens with $2 \%$ addition of zinc oxide and sodium nitrite show maximum improvement in the compressive, split tensile, flexural and bond strength when compared with the control specimen.

- The incorporation of inhibitors shows very lower permeability and water absorption. Over dosing of corrosion inhibitor results in the acceleration of setting time which leads to a reduction in the ultimate strength of concrete.

- All the corrosion test results revealed that $2 \%$ addition zinc oxide and sodium nitrite is found to be more effective in controlling the corrosion rate of steel. Zinc oxide protects embedded steel in concrete by reacting with the steel surface to interfere with the reduction of oxygen whereas sodium nitrite blocks the corrosion reaction of the chloride-ions by chemically reinforcing and stabilizing the passive protective film on the steel.

- Considering strength as well as corrosion resistance, the optimum percentage addition of inorganic inhibitors by weight of cement in concrete containing quarry dust as fine aggregate is found to be $2 \%$ for zinc oxide and sodium nitrite.

\section{REFERENCES}

1. R. Ilangovan and K. Nagamani, Application of Quarry Rock Dust as Fine Aggregate in Concrete Construction, National Journal on Construction Management: NJCMR, Pune, December, pp. 5-13 (2006).

2. H.A.F. Dehwah, Constr. Build. Mater, 37, 277 (2012).

3. R. Ilangovan and K. Nagamani, Studies on Strength and Behaviour of Concrete by Using Quarry Dust as Fine Aggregate, CE and CR Journal, New Delhi, October, pp. 40-42 (2006).

4. S.N. Raman, T. Ngo, P. Mendis, H.B. Mahmud, Constr. Build. Mater, 25, 3123 (2011).

5. A.K. Sahu, S. Kumar and A.K. Sachan, Indian Concrete J., 77, 845 (2003).

6. R. Murugesan, N.R. Chitra and P. Saravanakumar, Effect of Partial Replacement of sand by Quarry Dust in Concrete With and Without Super Plasticizer, Proceedings of the National Conference on Concrete Technology for the future, pp. 167-170 (2006).

7. E.P. Khamput, A Study of Compressive Strength of Concrete Using quarry dust as fine aggregate and mixing with admixture type E, Rajamangla University of Technology, Thanyaburi, Pathumthani, Thailand (2005).

8. D. Manning and J. Vetterlein, Explotation and Use of Quarry Fines, Report No: 087/MIST2/DACM/01, MST Project Reference: MA/2/4/ 2003.

9. P.A. Crane, Corrosion of Reinforcement in Concrete Construction, Society of Chemical Industry, Publishers Ellis Horwood Ltd., London, edn 1 (1983). 
10. H.-W. Song and V. Saraswathy, Int. J. Electrochem. Sci., 2, 1 (2007).

11. K. Videm, Corrosion of Reinforcement in concrete. Monitoring, Prevention and Rehabilitation, EFC No: 25. London, pp. 104-121.E (1998).

12. J. Prabakar, P. Devadas Manoharan and M. Neeklamegam, Performance Evaluation of Concrete Containing Sodium Nitrate inhibitor, Proceedings of the $11^{\text {th }}$ International Conference on Non-conventional Materials and Technologies 6-9, Bath, UK, pp. 1-12 (2009).

13. C. Andrade, C. Alonso, J. Fullea, J. Polimon and J. Rodriguez, Mater Struct., 37, 623 (2004).

14. T.M. Roberts and H. Haji-Kazemi, Int. J. Cement Compos. Lightweight Concr, 11, 21 (1989).

15. M.C. Brown, R.E. Weyers and M.M. Sprinkel, ACI Mater. J., 98, 240 (2001).

16. N.S. Berke and M.C. Hicks, Cement Concrete Comp., 26, 191 (2004).

17. G. De Schutter and L. Luo, Construct. Build. Mater, 18, 483 (2004).

18. P. Gu, S. Elliott, R. Hristova, J.J. Beaudoin, R. Brousseau and B. Baldock, ACI Mater. J., 94, 385 (1997).
19. D. Bone, Corrosion Inhibitors, Royal Haskoning, Current Practice Sheet No. 6, Concrete Bridge Development Group (1989).

20. B.B. Hope and A.K.C. Ip, ACI Mater. J., 86, 602 (1989).

21. H. Justnes, Corrosion Inhibitors for Concrete, Proceedings of the International Symposium on Durability of Concrete I Memory of Prof. Dr. Raymundo, Rivera, 12-1 Monterrey, N.L. México, pp. 179-199 (2005).

22. M.C. Brown, R.E. Weyers and M.M. Sprinkel, ACI Mater. J., 99, 371 (2002).

23. F.V. Munteanu and D.F. Kinney, Corrosion Inhibition Properties of a Complex Inhibitor-Mechanism of Inhibition, CANMET, pp. 255-269 (2000).

24. L. Luo and G. De Schutter, Mater. Struct., 41, 1571 (2008).

25. V.S. Ramachandran, Concrete Admixtures Handbook, Institute for Research in Construction, National Research Council Canada, Ottawa, Ontario, Canada (2002). 